\title{
Research on the Teaching Methods of Physics Course
}

\author{
Zhi Qiang Xu \\ Department of Physics and Technology, Kunming University, Kunming 650214, China \\ 2793436659@qq.com
}

Keywords: the teaching quality; teaching methods; teachers' training; teaching guidance; teaching evaluation

\begin{abstract}
The measures of improvement of physics course teaching will be deeply studied, such as excellent teaching methods, comprehensive teachers' training, scientific teaching guidance and efficient teaching evaluation. The study of these comprehensive, detailed, specific and practical measures can be of certain guidance significance to the teaching quality of physics course.
\end{abstract}

\section{Introduction}

"The Department of Physics at universities must have the dual functions- teaching and research ". It is under the guidance of this concept that teachers and students should devote to groundbreaking research, contributing to the continuous development of higher education. Nowadays, a new generation of physicists are continuing working on basic issues in all fields of physics and providing excellent and innovative physical education to students who are talented[1]. It is based on the concept that both teaching and research are important that we try to make unremitting efforts to ensure and enhance the teaching quality of physical course. Teaching methods, teachers' training, teaching guidance and teaching evaluation will be analyzed in this article in order to provide some references for improving the teaching quality of physics course at universities.

\section{Taking an interactive teaching method}

All that can promote students ' wisdom and touches students ' minds is the education of humanities education. This requires teachers put teaching materials to the teaching of physical culture in the context of understanding and design, combined with the current reality of social life, college students' development to explore the physics of the knowledge contained in scientific, social, and life of enlightening. Turn a static imparting to a dynamic evolution of knowledge and inspiration, cultivate students ' view of history and development, cultivate students' active participation in experimental operations and strengthen the ability of exercise consciousness, as well as students in a subtle sense of observation, analysis and scientific innovation. For example, in the teaching of "thin lens", in order to stimulate students' interest and curiosity, teachers should present to the students:" What is the first application of lens in scientific research?” Then the teacher describes how Galileo used the telescope with which he himself invented to observe and study the sky for the first time to discover a series of significant astronomical phenomena, showing Galileo's extraordinary dimensional real, truth-seeking, innovative scientific spirit; illustrating the role that physics and experiments play in the development of the natural science; introducing the value of scientific research that Galileo created by combining experiments and mathematics, as well as its influence on the development of science. In this way, vigor and vitality can be integrated with the history of science in the teaching activities. Not only the scientific qualities and cultivation of humanistic quality can be achieved, but also reflects the qualities and skills of education to new ideas.

The traditional teaching of physics stresses the theory of integrity and systemic, while student exercises are often designed for the idealized model. Learning physics for the students is to learn some flat physical symbols and formulas. Students cannot always link the physical knowledge to life worlds; while new situations put actual physical knowledge and life closely combine to enhance the application of physical problems and practice. Let physics go into the life of students, which enables students to face the challenges and makes them believe that high-tech is inscrutable. In the war of the 
Afghanistan, the US military used satellite technology to obtain the information of Taliban; Shouliang Ke leapt the Yellow River, China is constructing the maglev train in Shanghai, etc. Those examples stimulate a strong desire to learn physical concepts for students. When students really know that they are living in a world of physical phenomena, they will be interested in the power for studying physical knowledge and use it to create a great desire to learn this course. By means of traditional physics teaching, teachers only state physical concepts and knowledge from a variety of textbooks and lectures. Students just passively listen to them; rarely actively participate in the thinking activities. Teachers talk alone to a group of passive listeners. Therefore, under this kind of teaching model, it is not easy for teachers to make the students stay focused during the whole period, and it is even more difficult for the students to think critically through discussion. [2]When using an interactive teaching method, teachers can not only see how students understand the concepts by knowing students' answers in the concept tests. Teachers can participate in the discussion of the students by walking among the students in the classroom, listening or asking questions to discuss how the questions are solved. These feedback information not only provides the basis for the timely and appropriate teaching adjustments but also improves teaching continuously[3].

The problem originated from thinking is the beginning of creation. No problems means no innovation. From the ancient times to the present, the starting point of scientific research and innovation is not from the existing problem, but from the phenomenon and practice. Finding problems is an important part of scientific research. Once a student asks himself a question, it means he desires to solve it, forming the problem of consciousness. In this way, he is able to feel and detect keen and precise information. Problems make the point with selective attention on the ongoing. Just as Hisheen Fort once said: "Putting forward the right question often means having solved most part of the problems." One of the most famous physicists Zhengdao Li once said: "For researchers, the most important thing is whether they are be able to ask the right questions or not." The problem consciousness is one of the instincts of human beings, so is the humans' creation. If traditional teaching model is adopted for a long period of time, students will rarely ask questions and character of students will be affected, obliterating the personality development of students. Thus, the students will lose the deep-seated awareness of further exploration.

\section{Teaching by classic cases}

Studying physics is not just skillfully using the formula to solve the problem, but having a certain amount of judgment before you begin to calculate. Therefore, when studying a specific content or doing an exercise, focusing on the result only means staying on the surface of the question. Students will only know the physical phenomena instead of physical nature. Only in further process or results of solving problems and tracing the physical nature of problems can the physical facts be understood. For example, in a typical example of simple harmonic motion in spring oscillator, textbooks are arranged to use previously learned knowledge of the kinematics and dynamics to analyze a specific sport. We start with the physical abstract idealized model - spring oscillator, then analyze its force, use Newton's Second Law to list the dynamic differential equations and solve equations to the general equation of motion. Next, substitute into the initial conditions, determine the kinematic equations. The information of the spring oscillator motion can be known. From this content, we should be aware: The force of the object dominates the sports, once the initial conditions are determined, the state of the motion of the object is determined. In this way, we will recognize from a specific problem to a general conclusion

The image is both a "number" and "shape" combination of products and the comprehensive embodiment of "specific" and "abstract". It is not only the rich carrier of physical information, but also a interrelated link between the imagery thinking and the abstract thinking.It is one of the methods of scientific experiments which are widely used in analysis of experimental data, as well as one of the means which are commonly used in theoretical research. Images can vividly express the laws of physics, intuitively describe the physical process and clearly indicate the relationship between 
physical quantities. The intuitive and accurate experimental results will be obtained by using the image. In the process of problem solving, anything can be simplified easily. For some questions, it is complicated to solve them by means of the comprehensive analysis, the logical reasoning or the mathematical algorithm.However, an unexpected effect will be achieved if the image method is adopted.Thus, the image method is a indispensable aid in physical law and Experimental Teaching. So reasonable and smart use of the image method will achieve a multiplier effect.Take the electric field of the uniform sphere as an example, first make the Gaussian surface of the inside and outside of the ball, then obtain the electric field by using Gauss theorem. Next, obtain the electric field intensity, taking the distance as the horizontal ordinate and the size of the intensity of the electric field. Finally the distribution curve analysis and explanation will work best.

Cases teaching are a kind of teaching which generates students study by means of discussing, aiming at some of the scenes in their own life. The advantages of cases teaching arouses thinking, brainstorming and considering in different methods, drawing different conclusions. That is to say, there is not the only answer in cases teaching[4].Take a classic case as an example: how to make the least rain amount while walking in the rain? By modeling analysis, the results derived from the different models may be different. In that case, the column direction, the speed of the rainfall, the body shape (area), and many other factors should be considered, drawing different conclusions. Usually, if the rain is in front of you, run as fast as possible. If the rain is from the rear or side rear, and with lower speed, run as fast as possible; if the rain is from the rear or side rear, and with greater speed, making people stand in the rain, rain pours on the back more than on the rest parts of the body. It should be better to run avoiding the rainfall on the back. The case teaching can also be seen as a fun teaching. It can effectively mobilize the enthusiasm of students to think, arousing their awareness of innovation.

To encourage students to participate in various extracurricular activities, teachers can suggest extensively reading, taking physics course knowledge as the core, and forming a broad range of knowledge. Especially highly differentiated and integrated of science makes the entire science and technology an independent body structure and crisscrossed network system.In order to solve a certain physical problem, not only some related physical disciplines of knowledge and method are needed, but also a lot of knowledge and methods related to natural science, social sciences, and thinking science are required. Just as Taylor pointed out: "People who have rich knowledge and experience are more prone than those who have only one kind of knowledge and experience of association and insights," The Nobel Physics Award winner Giaever has a series of formal background knowledge in machinery, electricity, military, and philosophy. When he became fascinated with physics, he boldly and decisively affirmed "Let tunnel effect and phenomenon of superconductivity unite". He discovered tunneling effect of the electron in superconducting and theoretically predicted the possibility that supper current can go through the tunnel barrier layer.

\section{The improved curriculum design and courses discussion system}

The course syllabus should be submitted and uploaded to the website for students to view physics course by physics teachers before the beginning of a new semester. On the one hand, the curriculum allows students to know the purpose and the general situation of the course; on the other hand, the course syllabus can be used as a contract between teachers and students. Thus it can be expected to arrange assignment as well as evaluate students' achievement. Besides, the syllabus may also be used as the guiding reference[5]. Referring to it, students and teachers can learn some information, such as the curriculum and the teaching schedule. Furthermore, it can be used as the foundation of curriculum teaching methods and the content of the course. In general, the curriculum should include learning objectives, the basic principle of the course, the fundamental information of the course, the content of course, student tasks, the methods of the achievement evaluation, course materials, access ways and teaching philosophy, etc. 
In addition to making efforts to mobilize students' learning and creative passion, students can be divided into several large groups according to different experiments. The team leader is the direct assistant to the teacher, and then divides them into small groups according to the instruments. The team leader can be the indirect assistant to the teacher. The team leaders should understand the actual situation of the students in the experiment. The feedback of requirements and recommendations of students will be given to the teachers timely. Teachers target answers to the problems which students encounter in the experiment, adjust teaching concepts and improve teaching methods. Meanwhile the requirements and the intent of the teachers can also be fed back to the students. It enables students to complete the experiment better. For example, if some students do not seriously deal with the experiment preview report, the assistant may suggest checking the preview circumstances by ask questions before the experiment, and the sore is included in the usual grade. The adoption of this proposal results in an increase of "usual question" assessment, greatly increasing the enthusiasm of the students. The exchange between teachers and students becomes easier, smoother, and more harmonious because of the assistants.

Physics teachers should pay more attention to the interaction between teachers and students, focusing on the "learning" of students rather than the "teaching" of teachers. They should also watch the learning processes and the learning outcome of the students and emphasize the understanding of the physics concepts. Therefore, seminar teaching can be applied to physics teaching[6]. Teachers not only know the scope and the whereabouts of the seminar, but also have the ability to track all issues and impromptu comments and find ways for giving appropriate responses to each student. Teachers use questions, listening, responding and commenting as the basic structure of the seminar [7]. A special center to train teachers should provide teachers with quite a lot of information on how to organize seminars. Technology, methods, problems and the systematic tutorial about the teaching method should be included, which aims to improve the ability of teachers to organize seminar. In addition, classic tapes about physics seminars should be provided to physics teachers[8 ].

\section{Conclusion}

In many years of teaching practice, through constant learning from other colleges and the experience of their predecessors, according to the professional training objectives and characteristics, the use of modern teaching methods are distinguished. Combined with the actual situation, teachers highlight a general principle, the teaching method and training. Be sure to clarify the concepts of physics, actively study the practical teaching methods as well as adopt high quality and efficient teaching methods. If teachers try to stimulate the enthusiasm of students to learn this course, students can master the basic concepts, understand the basic theoretical system. At the same time, they can understand the application. The most important is that students can get the access to basic theoretical analysis and problem-solving abilities. The research on teaching methods and reform will be of a certain theoretical and practical significance for the promotion of teaching.

\section{References}

[1]. Mazur. Peer Instruction:A user's manual[J]. NJ:Pren tice Hall, 1997:10-16.

[2]. Gautroau R, Novemsky L. Concepts first-A small group approach to physics learning [ J]. American Journal of Physics, 1997, 65 (5):418-428.

[3]. Catherine H, Crouch, Mazur. Peer Instruction: Ten years of experience and results [ J ]. American Journal of Physics, 2001,69 (90):970-977.

[4]. Mazur. Farewell, Lecture [J]. SCIENCE, 2009, 323 ( 1 ) :50-

[5]. Courses Plans.http://isites. Harvard. edu/ieb/icb. do? Key word = k1985\&pageid = icb. page29695. In Chinese 
[6]. The Art of questioning http://isites. Harvard. du/fs/html/icb.topic58474/questioning. html. In Chinese

[7]. The Art of responding .http://isites. Harvard. edu/fs/html/icb.topic58474/responding. html. In Chinese

[8]. The Leading Strategies of Effective Discussion.http://isites. harvard. edu/fs/html/icb. topic58474/Dawes_DL. html. In Chinese 